\title{
Tratamentos invasivos da neuralgia trigeminal: uma revisão sistemática
}

\author{
Lina Miyuri Suizu' ${ }^{10}$, Emanuelle Nonato Coelho de Souza' ${ }^{10}$, Luiz Otávio Silva da Silva Filho' ${ }^{(\mathbb{D})}$, \\ Beatriz Suarez Jerez ${ }^{2}$ (D) Franklin Reis $^{3}$ (i)
}

'Centro universitário FAMETRO, Manaus, Amazonas, Brasil

${ }^{2}$ Universidade Nilton Lins, Manaus, Amazonas, Brasil.

${ }^{3}$ Hospital Adventista de Manaus, Manaus, Amazonas, Brasil.

\section{Introdução}

A neuralgia do trigeminal resulta em uma síndrome dolorosa crônica de etiologia ampla, a maioria relacionada à compressão vascular. O tratamento dessa patologia pode variar conforme o grau de comprometimento e resposta à terapêutica aplicada. Existem variadas formas de tratamento, desde os conservadores até procedimentos invasivos e minimamente invasivos.

\section{Objetivos}

Identificar os tratamentos invasivos mais utilizados, avaliar sua eficácia e segurança na abordagem ao paciente

\section{Material e Métodos}

Trata-se de uma revisão sistemática, que envolve artigos no período de 2011 a 2021 em três bases de dados: PubMed, Science Direct e SciElo utilizando os MeSH terms: "invasive treatment" e "trigeminal neuralgia". Após a aplicação de critérios de exclusão, 34 artigos foram selecionados.

\section{Resultados}

Viu-se que a técnica mais testada para o tratamento invasivo da neuralgia trigeminal foi a Neuroestimulação, com 44, $1 \%$ dos artigos descrevendo suas aplicações, seguida da Descompressão Microvascular com 29,4\% dos artigos. A cirurgia de compressão por Balão (17,64\%), Rizólises e Rizotomias (17,64\%), Gamma Knife (14,7\%) e as técnicas de Termocoagulação e Termorregulação (8,82\%). Todos apresentaram taxas elevadas e semelhantes de eficácia, com alívio imediato da dor apesar da frequente necessidade de reaplicar o procedimento após meses ou anos.

\section{Conclusão}

Provou-se difícil classificar o melhor tratamento invasivo, visto que as taxas de eficácia e as complicações dos procedimentos são extremamente semelhantes. Uma conclusão viável é a de que o procedimento escolhido seja individualizado conforme as necessidades e particularidades de cada paciente, associado à experiência do médico especialista.

Palavras-chave: Cefaléia Crônica, Neuralgia do Trigêmeo, Cirurgia de Descompressão Microvascular, Procedimento Cirúrgico Minimamente Invasivo. 